Vol. 8, Issue 6, June 2019

\title{
A Study on Future of Electric Vehicles in India
}

\author{
Indukala M. P. ${ }^{1}$, Bincy M. Mathew ${ }^{2}$ \\ HOD, Department of EEE, St. Mary’s Polytechnic College, Palakkad, India ${ }^{1}$ \\ Faculty, Department of EEE, St. Mary’s Polytechnic, Palakkad, India ${ }^{2}$
}

\begin{abstract}
This paper discusses about the future of Electric Vehicles in India. The world is rapidly moving towards electric mobility. Under the Clean Energy Ministerial, a high-level forum to promote clean energy policies and programmes, eight countries have committed to the 'EV 30@30' campaign. As part of the campaign, the countries, of which India is a member, aim to achieve a 30 percent electric vehicle penetration by 2030 . There are clearly many positives to electric vehicles but several challenges are to be met to accelerate electric mobility. Deployment of a reliable Charging Infrastructure is the key to drive EV penetration in the country. Additionally, suitably addressing the issues of Range Anxiety and Charging Time will be pivotal in the proliferation of E-mobility. Easy and affordable access to charging infrastructure - both standard AC charging as well as rapid DC charging - also plays a central role in meeting customer needs. Effects on the grid due to EV charging needs and other such impacts are to be assessed and addressed suitably.
\end{abstract}

Keywords: Electric Vehicles, Battery Electric Vehicles, Hybrid Electric Vehicles, Plug-In Hybrid Electric Vehicles, Fuel Cell Electric Vehicle, Electric Vehicle Charging Infrastructure

\section{INTRODUCTION}

The future of electric transportation is evolving rapidly. India is one of the top ten automotive markets in the world today and having highly increasing middle class population with buying potential and the steady economic growth. India's road transport sector accounts for 25 to 27 percent of crude oil consumed in the country, and, according to the National Green Tribunal (NGT), vehicular emission is one of the major sources of India's urban pollution. Hence, adoption of low-emission transport solutions like electric vehicles is the need of the hour. The government's recent announcements on phase-II of the Faster Adoption and Manufacturing of (Hybrid \&) Electric Vehicles scheme (FAME II), which will be implemented between 2019 to 2022, and road tax and registration charge exemption for hybrids and Electric Vehicles(EVs), will bring a major turnaround in growing India's EV space. The availability of EV charging infrastructure is fundamental to the growth of EVs. Advancement in battery technology and falling price of battery shall increase the market penetration of electric vehicles. Also, emissions regulations getting tighter would push the automobile manufacturers toward production of electric vehicles. In spite of the benefits EV provides for environment, for customers, for the nation's energy grid, and for national security, it is required to overcome several technical, social and economic barriers for its large scale adoption.

\section{GLOBAL SCENARIO}

Historically, mobility and fossil fuels have been inextricably linked with electric vehicles being successful only in few markets. However, over 2 million electric vehicles were sold in 2018, up from just a few thousand in 2010, and there is no sign of slowing down. Passenger EV sales is expected to rise to 10 million in 2025, 28 million in 2030 and 56 million by 2040. According to Electric Vehicle Outlook 2019, BloombergNEF, by 2040, 57\% of all passenger vehicle sales, and over $30 \%$ of the global passenger vehicle fleet, will be electric. A collection of circumstances created an opening for electric mobility to enter the mass market and it includes

\section{A. Climatic change}

The prospect of rapid global temperature increase has created the need for a reduction in the use of fossil fuels and the associated emissions.

\section{B. Advances in renewable energy}

Over the last decade, advances in wind and solar electricity generation technologies have drastically reduced their cost and introduced the possibility of clean, low-carbon and inexpensive grids.

C. Rapid urbanization

Economic development, especially in emerging economies, is creating a wave of urbanization as rural populations move to cities in search of employment. While urbanization is an important component of the process of economic development, it also stresses upon the energy and transport infrastructure leading to congestion and pollution. Electric vehicles (EVs) can improve that scenario by reducing local concentrations of pollutants in cities. 


\title{
International Journal of Advanced Research in Computer and Communication Engineering
}

\author{
Vol. 8, Issue 6, June 2019
}

D. Battery chemistry

Advances in battery technology have led to higher energy densities, faster charging and reduced battery degradation from charging. Combined with the development of motors with higher rating and reliability, these improvements in battery chemistry have reduced costs and improved the performance and efficiency of electric vehicles.

E. Energy security

The petrol, diesel and CNG needed to fuel an internal combustion engine (ICE) based mobility system requires an extensive costly supply chain that is prone to disruption from weather, geopolitical events and other factors. Electric Mobility reduces energy security related issues.

\section{INDIAN SCENARIO}

India has a unique mobility pattern which other countries do not share. India uses a large variety of motorized transport on roads and its auto-segments are quite different from that of most of the world. Also, India has a particular set of circumstances which are conducive to adoption of EVs over ICE vehicles. These are:

1. A relative abundance of exploitable renewable energy resources.

2. High availability of skilled manpower and technology.

3. An infrastructure and consumer transition that affords opportunities to apply technologies to leapfrog stages of development.

4. A universal culture that accepts and promotes sharing of assets and resources for the overall common good. India started its e-mobility journey in 2011, with the launch of the National Mission for Electric Mobility (NMEM). Energy Efficient Services Limited (EESL), a joint venture of national Public-Sector Undertakings under Ministry of Power, forayed into e-mobility in 2017 by floating a tender for 10,000 e-cars for use in public offices to provide encouragement for Indian e-vehicle manufacturers, charging infrastructure companies and service providers to gain efficiencies of scale and drive down costs in the electric mobility ecosystem.

India's electric mobility vision has several dimensions. In terms of numbers, India will be, with an estimated 400 million customers in need of mobility by 2030, one of the largest auto markets in the world. If powered by conventional, greenhouse gas emitting fossil fuels, India's mobility choices will set back the environmental sustainability agenda, while increasing imported fossil fuel dependence.

The government's recent announcements on phase-II of the Faster Adoption and Manufacturing of (Hybrid \&) Electric Vehicles scheme (FAME II), which will be implemented between 2019 to 2022, and road tax and registration charge exemption for hybrids and EVs, will bring a major turnaround in growing India's EV space. The Centre has also asked states to frame their EV policy and provide additional fiscal and non-fiscal incentives to manufacturers and buyers. Many Indian states have taken the initiative to enable the policy framework for electric mobility. While Delhi, Kerala and Uttar Pradesh have already published their draft electric vehicle policies, others states, such as Andhra Pradesh, have notified the policy and are in the implementation phase. The key objectives of the India's EV policy are:

1. Reduce primary oil consumption in transportation.

2. Facilitate customer adoption of electric and clean energy vehicles.

3. Encourage cutting edge technology in India through adoption, adaptation and research \& development.

4. Improve transportation used by the common man for personal and goods transportation.

5. Reduce pollution in cities.

6. Create EV manufacturing capacity that is of global scale and competitiveness.

7. Facilitate employment growth in EV sector.

Almost all car manufacturers are planning to enter into EV sector. Tata and Mahindra already have EVs in their portfolio (though in very small numbers), Maruti Suzuki, Ford, Hyundai, Toyota, Kia, MG Motors and others are all testing and planning to launch their own EVs within the next few years. None of these manufacturers are delusional about the mass market prospects for EVs, but they are hopeful that the policy push from the Government will translate into concrete steps that will eventually make EVs attractive even for buyers in the lower price segments.

\section{TYPES OF ELECTRIC VEHICLES}

EVs can run solely on electric propulsion or they can have an ICE working alongside it. Having only batteries as energy source constitutes the basic kind of EV, but there are kinds that can employ other energy sources as well. EVs can be categorized as follows:

\section{A. Battery Electric Vehicle (BEV)}

EVs with only batteries to provide power to the drive train are known as BEVs. BEVs have to rely solely on the energy stored in their battery packs; therefore the range of such vehicles depends directly on the battery capacity. Typically they can cover $100 \mathrm{Km}-250 \mathrm{Km}$ on one charge, whereas the top-tier models can go a lot further, from $300 \mathrm{Km}$ to 500 $\mathrm{Km}$. These ranges depend on driving condition and style, vehicle configurations, road conditions, climate, battery type 
and age. Once depleted, charging the battery pack takes quite a lot of time compared to refueling a conventional ICE vehicle. It can take as long as 36 hours to completely replenish the batteries. Though there are far less time consuming ones as well, none is comparable to the little time required to refill a fuel tank. Charging time of BEV depends on the charger configuration, its infrastructure and operating power level. Advantages of BEVs are their simple construction, operation and convenience. These do not produce any greenhouse gas (GHG), do not create any noise and therefore is beneficial to the environment. Electric propulsion provides instant and high torques, even at low speeds. These advantages, coupled with their limitation of range, makes them the perfect vehicle to use in urban areas; as urban driving requires running at slow or medium speeds, and these ranges demand a lot of torque. Nissan Leaf and Tesla are some high-selling BEVs these days, along with some Chinese vehicles.

\section{B. Hybrid Electric Vehicle (HEV)}

HEVs employ both an ICE and an electrical power train to power the vehicle. The combination of these two can come in different forms. An HEV uses the electric propulsion system when the power demand is low. When higher speed is needed, the HEV switches to the ICE. The two drive trains can also work together to improve the performance. The ICE can charge up the batteries, HEVs can also retrieve energy by means of regenerative braking. Therefore, HEVs are primarily ICE driven cars that use an electrical drive train to improve mileage or for performance enhancement.

\section{Plug-In Hybrid Electric Vehicle (PHEV)}

PHEVs start in 'all electric' mode, runs on electricity and when the batteries are low in charge, it calls on the ICE to provide a boost or to charge up the battery pack. The ICE is used here to extend the range. PHEVs can charge their batteries directly from the grid which HEVs cannot; they also have the facility to utilize regenerative braking. PHEVs' ability to run solely on electricity for most of the time makes its carbon footprint smaller than the HEVs. They consume less fuel as well and thus reduce the associated cost. The vehicle market is now quite populated with these, Chevrolet Volt and Toyota Prius sales show their popularity as well.

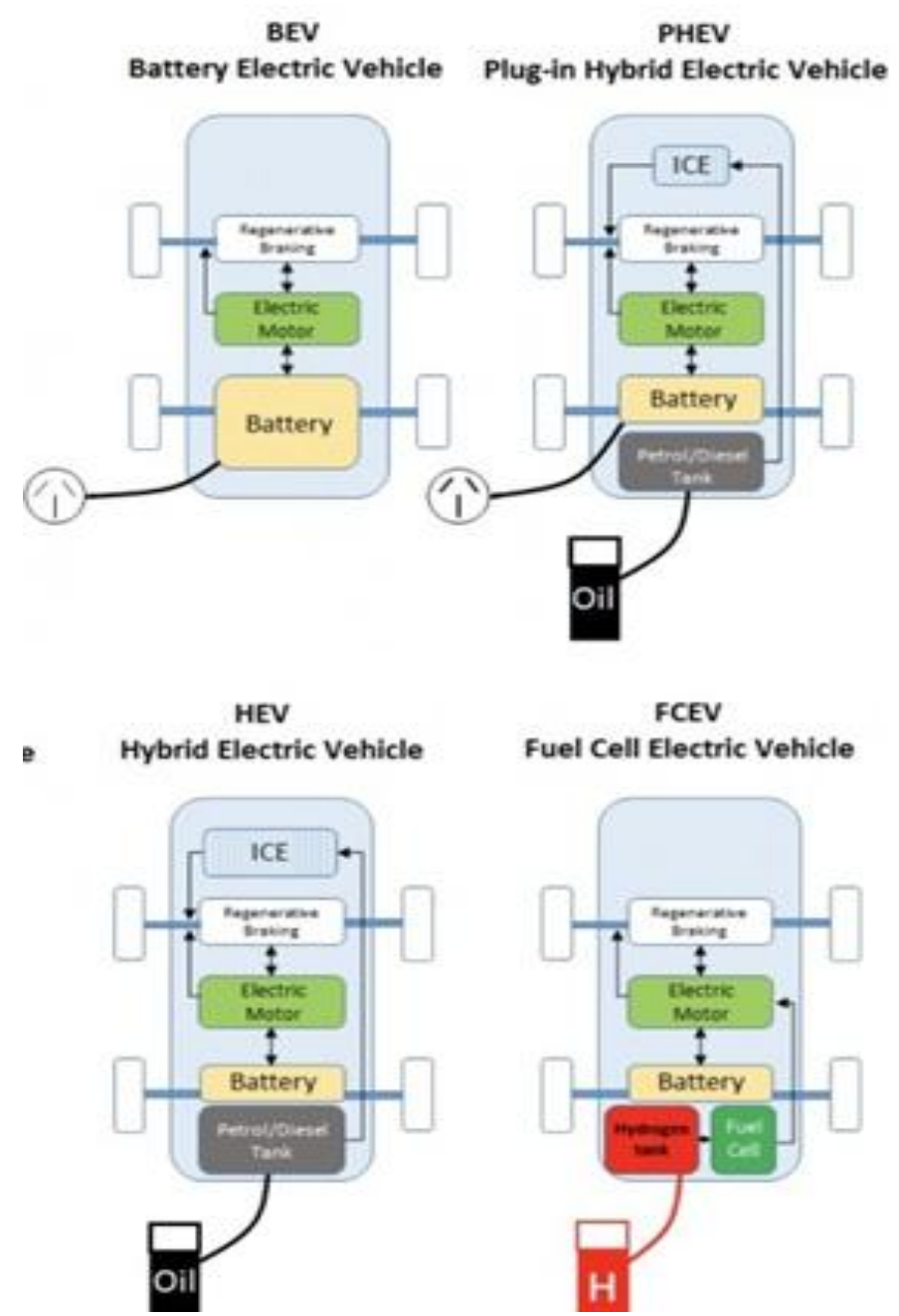

Fig. 1 Types of Electric Vehicles 
Vol. 8, Issue 6, June 2019

D. Fuel Cell Electric Vehicle (FCEV)

In FCEV, fuel cells that use chemical reactions to produce electricity are used as energy source. Hydrogen is the fuel of choice for FCEVs, so they are often called 'hydrogen fuel cell vehicles'. FCEVs carry the hydrogen in special high pressure tanks and another ingredient for the power generating process is oxygen, which it acquires from the air sucked in from the environment. Electricity generated from the fuel cells goes to an electric motor which drives the wheels. Excess energy is stored in storage systems like batteries or super capacitors. Commercially available FCEVs like the Toyota Mirai or Honda Clarity use batteries for this purpose. FCEVs produce only water as a byproduct of its power generating process which is ejected out of the car through the tailpipes. An advantage of such vehicles is they can produce their own electricity which emits no carbon, enabling it to reduce its carbon footprint further than any other EV. Another major advantage of these are, and maybe the most important one right now, refilling these vehicles takes the same amount of time required to fill a conventional vehicle at a gas pump. This makes adoption of these vehicles more likely in the near future. A major current obstacle in adopting this technology is the scarcity of hydrogen fuel stations. There are also concerns regarding safety in case of flammable hydrogen leaking out of the tanks. If these obstacles were eliminated, FCEVs could really represent the future of cars.

\section{BENEFITS OF ELECTRIC VEHICLES}

EVs provide major benefits for the environment, for customers, for the nation's energy grid, and for national security.

\section{A. Environmental Benefits}

EVs can reduce the emissions that contribute to climate change and smog, improving public health and reducing ecological damage. Charging EV on renewable energy such as solar or wind minimizes these emissions even more.

B. Customer Benefits

EVs are cheaper to operate than gasoline vehicles, primarily due to the lower cost of electricity on an equivalent cost basis and also due to lower maintenance costs.

C. Energy Grid Benefits

EVs coupled with managed charging, result in more efficient utilization of the energy grid, which lowers the average cost.

D. National Security Benefits

When EVs plug in, they are 100 percent powered by a domestic mix of energy sources, including natural gas, coal, nuclear, hydropower, wind, and solar. This is in stark contrast to gasoline-fueled vehicles, which depend solely on oil which is imported.

\section{BARRIERS TO ADOPTION OF ELECTRIC VEHICLES}

Electric Vehicles are promoted as a viable near-term vehicle technology to reduce dependence on fossil fuels and resulting greenhouse gas emissions associated with conventional vehicles. In spite of several benefits of EVs, there are potential socio-technical and economic barriers to consumer adoption of EVs.

\section{A. Technological Problems}

Drawbacks related technology remains as a major barrier to adoption of EVs. Batteries are the main area of concern as their contribution to the weight of the car is significant. Technological barriers includes:

1. Limited Range: EVs are held back by the capacity of their batteries. They can travel only a distance that the stored energy allows. The range also depends on the speed of the vehicle, driving style, cargo the vehicle is carrying, the terrain it is being driven on, and the energy consuming services running in the car, for example air conditioning. This causes 'range anxiety' among the users. Though even the current BEVs are capable of traversing equivalent or more distance than a conventional vehicle can travel with a full tank, range anxiety remains a major obstacle for EVs to overcome.

2. Long Charging Period and charging rate of batteries: Another major downside of EVs is the long time they need to get charged. Depending on the type of charger and battery pack, charging can take from a few minutes to hours; this truly makes EVs incompetent against the ICE vehicles which only take a few minutes to get refueled. Some fast charging facilities are available at present, and more are being studied. There are also the fuel cell vehicles that do not require charging like other EVs. Filling up the hydrogen tank is all that has to be done in case of these vehicles, which is as convenient as filling up a fuel tank, but FCEVs need sufficient hydrogen refueling stations and a feasible way to produce the hydrogen in order to thrive. All EV batteries cannot be fast charged and Charging rate $(\mathrm{C}$-rate) of battery is the deciding factor. $1 \mathrm{C}$ rate refers to full charging in one hour; $2 \mathrm{C}$ rate refers to full charging in 30 minutes; and $10 \mathrm{C}$ refers to full charging in 6 minutes. And C/2 means two hours to fully charge. Maximum rate at which various types of batteries can be charged are given in the table below: 
Vol. 8, Issue 6, June 2019

Table I Charging Rate of Batteries

\begin{tabular}{|l|c|c|c|c|c|}
\hline $\begin{array}{c}\text { Battery } \\
\text { Chemistry }\end{array}$ & $\begin{array}{c}\text { Max. } \\
\text { C Rate }\end{array}$ & $\begin{array}{c}\text { Max. Temp. } \\
\text { (Deg. C) }\end{array}$ & $\begin{array}{c}\text { Life } \\
\text { (Max. Cycles) }\end{array}$ & $\begin{array}{c}\text { Power Density } \\
\text { (Wh/Kg) }\end{array}$ & $\begin{array}{c}\text { Avg. Module Price } \\
\text { (US\$/KWh in 2018) }\end{array}$ \\
\hline LFP & Up to 2C & 40 & $1500-3000$ & $100-130$ & 270 \\
\hline NMC & C/2 & 40 & $1000-2000$ & $230-250$ & 250 \\
\hline NMC & 3C & 40 & $3000-4000$ & $200-250$ & 400 \\
\hline NCA & 2C & 40 & $1000-1500$ & $250-270$ & 230 \\
\hline LTO & 6C & 60 & $7500-10000$ & $50-80$ & 700 \\
\hline
\end{tabular}

3. Safety Concerns: The concerns about safety are rising mainly about the FCEVs nowadays. There are speculations that, if hydrogen escapes the tanks it can cause serious harm, as it is highly flammable. It has no color either, making a leak hard to notice. There is also the chance of the hydrogen tanks getting exploded, in case of a collision. To counter these problems, the automakers have taken measures to ensure the integrity of the tanks; they are wrapped with carbon fibers in case of the Toyota Mirai. In this car, the hydrogen handling parts are placed outside the cabin, allowing the gas to disperse easily in case of any leak, there are also arrangements to seal the tank outlet in case of high-speed collision.

B. Social Problems

1. Social Acceptance: The acceptance of a new and immature technology, along with its consequences, takes some time in the society as it means change of certain habits. Using an EV instead of a conventional vehicle means change of driving patters, refueling habits, preparedness to use an alternative transport in case of low battery, and these are not easy to adopt.

2. Insufficient Charging Stations: Though public charging stations have increased a lot in number, still they are not enough. Coupled with the lengthy charging time, this acts as a major deterrent against EV penetration. Not all the public charging stations may be compatible with every car as well; therefore it also becomes a challenge to find a proper charging point when it is required to replete the battery. But, the manufacturers are working on to mitigate this problem. Tesla and Nissan have been expanding their own charging networks, as it, in turn means they can sell more of their EVs. Hydrogen refueling stations are not abundant yet as well which is necessary to increase the adoption of FCEVs.

C. Economic Problems

The price of the EVs is quite high compared to their ICE counterparts. This is because of the high cost of batteries and fuel cells. To make people overlook this factor, governments in different countries are providing incentives and tax breaks which provide the buyers of EVs with subsidies. Mass production and technological advancements will lead to a decrease in the prices of batteries as well as fuel cells.

\section{IMPACT OF ELECTRIC VEHICLES}

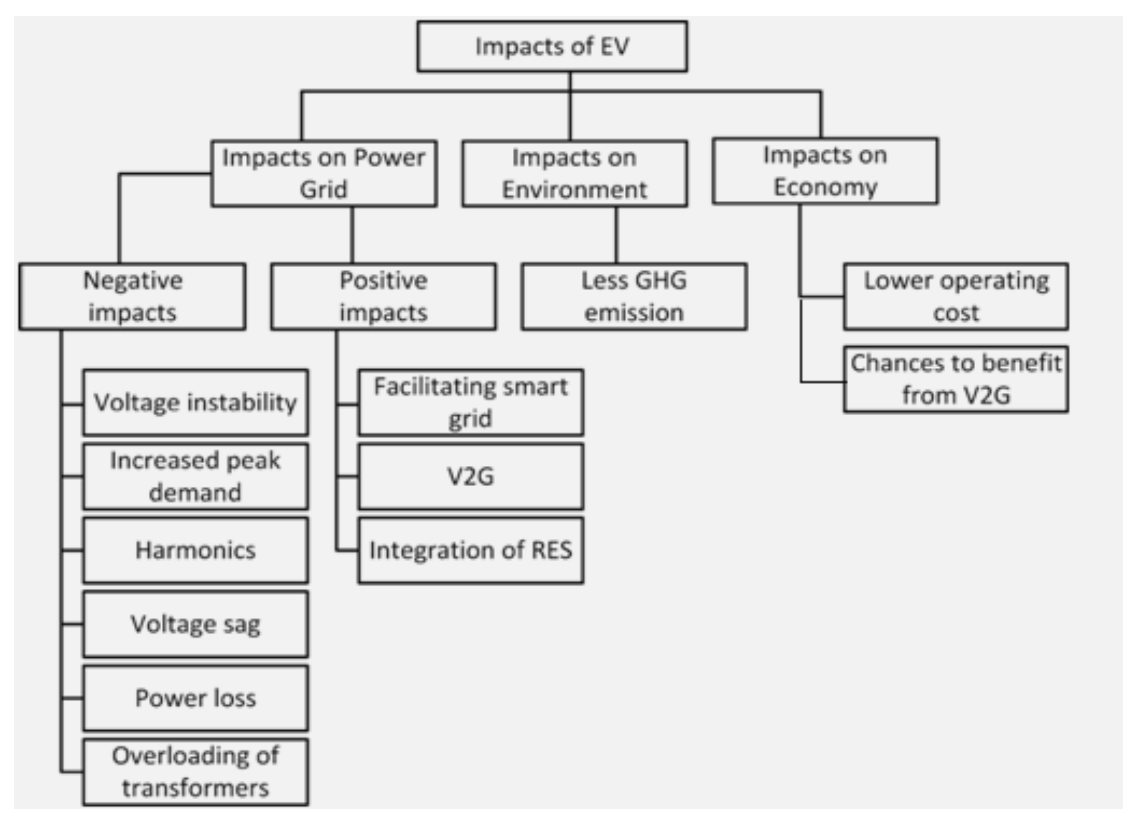

Fig. 2 Impacts of Electric Vehicles 
Vehicles may serve the purpose of transportation, but they affect a lot of other areas. The shift in the vehicle world created by EVs would impact the environment, the economy, and being electric, the electrical systems to a great extent. EVs are gaining popularity because of the benefits they provide in all these areas, but with them, there come some problems as well.

\section{A. Impact on the Power Grid}

EV's have both positive and negative impacts on Power Grid. EVs are considered to be high power loads and they affect the power distribution system directly; the distribution transformers, cables and fuses are affected by it the most. The situation gets quite alarming if charging is done during peak hours, leading to overload on the system, damage of the system equipment, tripping of protection relays, and subsequently, an increase in the infrastructure cost. To avoid these effects, and to provide efficient charging with the available infrastructure, coordinated charging (also called controlled or smart charging) has to be adopted. In this scheme, the EVs are charged during the time periods when the demand is low, for example, after midnight. Such schemes are beneficial in a lot of ways. It not only prevents addition of extra load during peak hours, but also increases the load in valley areas of the load curve, facilitating proper use of the power plants with better efficiency.

The major problems that are faced in the power systems because of EVs can be charted as following:

1. Voltage instability: Normally power systems are operated close to their stability limit. EV loads have nonlinear characteristics, which are different than the general industrial or domestic loads, and draw large quantities power in a short time period causing serious voltage instability in power systems. If the EVs have constant impedance load characteristics, then it is possible for the grid to support a lot of vehicles without facing any instability. However, the EV loads cannot be assumed beforehand and thus their power consumptions stay unpredictable; addition of a lot of EVs at a time therefore can lead to violation of distribution constraints.

2. Harmonics: The EV charger characteristics, being nonlinear, gives raise high frequency components of current and voltage, known as harmonics. Harmonics distort the voltage and current waveforms and thus reduce the power quality. It also causes stress in the power system equipment like cables and fuses.

3. Voltage sag: A decrease in the RMS value of voltage for half a cycle or $1 \mathrm{~min}$ is denoted as voltage sag. It can be caused by overload or during the starting of electric machines. Simulation modeled with an EV charger and a power converter stated $20 \% \mathrm{EV}$ penetration can exceed the voltage sag limit. Application of smart grid can help in great extents in mitigating the sag.

4. Power loss: Increased power loss as high as $40 \%$ can be expected. Uncoordinated charging can increase the amount of loss further more.

5. Overloading of transformers: EV charging directly affects the distribution transformers. The extra heat generated by EV loads can lead to increased aging rate of the transformers, but it also depends on the ambient temperature. In places with generally cold weather, the aging due to temperature is negligible.

6. Power quality degradation: The increased amount of harmonics and imbalance in voltage will degrade the power quality in case of massive scale EV penetration to the grid.

EVs can prove to be quite useful to the power systems in a number of ways:

1. Smart grid: In the smart grid system, intelligent communication and decision making is incorporated with the grid architecture. Smart grid is highly regarded as the future of power grids and offers a vast array of advantages to offer reliable power supply and advanced control. In such a system, the much coveted coordinated charging is easily achievable as interaction with the grid system becomes very much convenient even from the user end. The interaction of EVs and smart grid can facilitate opportunities like V2G and better integration of renewable energy. In fact, EV is one the priorities listed to create an efficient smart grid.

2. V2G: V2G or vehicle to grid is a method where the EV can provide power to the grid. In this system, the vehicles act as loads when they are drawing energy, and then can become dynamic energy storages by feeding back the energy to the grid. EV loads are applied in the valley points of the load curve, in V2G; EVs can act as power sources during peak hours. V2G is realizable with the smart grid system.

B. Integration of renewable energy sources

Renewable energy usage becomes more promising with EVs integrated into the picture. EV owners can use Renewable Energy Sources (RES) to generate power locally to charge their EVs. Parking lot roofs have high potential for the placement of PV panels which can charge the vehicles parked underneath as well as supplying the grid in case of excess generation, thus serving the increase of commercial RES deployment. 
C. Impact on Environment

One of the main factors that propelled the increase of EVs' popularity is their contribution to reduce the greenhouse gas (GHG) emissions. Conventional internal combustion engine (ICE) vehicles burn fuels directly and thus produce harmful gases, including carbon dioxide and carbon monoxide. Though HEVs and PHEVs have IC engines, their emissions are less than the conventional vehicles. But there are also theories that the electrical energy consumed by the EVs can give rise to GHG emission from the power plants which have to produce more because of the extra load added in form of EVs. This theory can be justified by the fact that the peak load power plants are likely to be ICE type, or can use gas or coal for power generation. If EVs add excess load during peak hours, it will lead to the operation of such plants and will give rise to $\mathrm{CO}_{2}$ emission. However, all the power is not generated from such resources. There are many other power generating technologies that produce less GHG. With those considered, the GHG production from power plants because of EV penetration is less than the amount produced by equivalent power generation from ICE vehicles. The power plants also produce energy in bulk, thus minimizing the per unit emission. With renewable sources integrated properly, which the EVs can support strongly, the emission from both power generation and transportation sector can be reduced. Over the lifetime, EVs cause less emission than conventional vehicles. Denmark managed to reduce $85 \% \mathrm{CO}_{2}$ emission from transportation by combining EVs and electric power. EVs also produce far less noise, which can highly reduce sound pollution, mostly in urban areas. The recycling of the batteries raises serious concerns though, as there are few organizations capable of recycling the lithium-ion batteries fully.

\section{Impact on Economy}

From the perspective of the EV owners, EVs provide less operating cost because of their superior efficiency; it can be up to $70 \%$ where ICE vehicles have efficiencies in the range of $60 \%$ to $70 \%$. The current high cost of EVs is likely to come down from mass production and better energy policies which will further increase the economic gains of the owners. V2G also allows the owners to obtain a financial benefit from their vehicles by providing service to the grid. The power service providers benefit from EV integration mainly by implementing coordinated charging and V2G. It allows them to adopt better peak handling strategies as well as to integrate renewable sources.

\section{CHARGING INFRASTRUCTURE}

The availability of Electric Vehicle Charging Infrastructure (EVCI) is fundamental to the growth of EVs. Although the initial investment for EV is around 1.5 times than conventional IC engine, but time has come when cost of environment is now more of concern than the cost of vehicle. EV charging and battery swapping are two means for providing energy to EV. Both the charging as well as swapping service would require that EVs have standard charging protocols. Government of India have undertaken several initiatives to promote manufacturing and adoption of electric vehicles in India. In order to make adequate EVCI available, Ministry of Power and Ministry of Housing \& Urban Affairs of Government of India has put forth guidelines and standards for development of EVCI. Also, necessary amendments have been made in existing laws and a detailed framework has been published in December 2018. The guidelines on Electric Vehicle Charging Infrastructure have been circulated to all the State Governments and UT Administrations with the request to amend their Building Byelaws and Master Plan Regulations. According to the latest framework Electric Vehicle Charging Infrastructure (EVCI) can be broadly classified into two

1. Private charging facilities at residences/offices: Distribution Companies of India (DISCOMs) shall facilitate private charging facilities at residences/offices.

2. Public Charging Stations (PCS): Setting up of Public Charging Stations (PCS) is a de-licensed activity and any individual/entity shall set up PCS, provided that they meet technical as well as performance standards and protocols laid down by Ministry of Power and Central Electricity Authority from time to time.

Also, any charging station may also obtain electricity from any generation company through open access protocols. The main EVCI characteristics that differentiate chargers include

1. Power and voltage levels: The output power range and voltage range supported by an EVCI.

2. AC or DC: Whether the output of EVCI is AC or DC; if it is AC, the vehicle needs to have an on-board charger.

3. Type: The output socket and connector used by an EVCI.

4. Mode: The communication protocol between the vehicle and the charger.

Currently, most vehicle manufacturers use the internationally approved CCS and CHAdeMO standards. Hence, PCS shall have one or more electric kiosks/boards with installation of all of the charger models as follows: 
Vol. 8, Issue 6, June 2019

Table I Charger Specifications For Pcs

\begin{tabular}{|c|c|c|}
\hline Charger Connectors* & $\begin{array}{c}\text { Rated } \\
\text { Voltage (V) }\end{array}$ & $\begin{array}{l}\text { No. of Charging } \\
\text { Points/No. of } \\
\text { Connector guns } \\
\text { (CG) }\end{array}$ \\
\hline $\operatorname{CCS}(\min 50 \mathrm{~kW})$ & $200-1000$ & $1 / 1 \mathrm{CG}$ \\
\hline CHAdeMO $(\min 50$ kW) & $200-1000$ & $1 / 1 \mathrm{CG}$ \\
\hline Type-2 AC (min 22 kW) & $380-480$ & $1 / 1 \mathrm{CG}$ \\
\hline Bharat DC-001 (15 kW) & $72-200$ & $1 / 1 \mathrm{CG}$ \\
\hline Bharat AC-001 (10 kW) & 230 & $3 / 3 \mathrm{CG}$ of $3.3 \mathrm{~kW}$ each \\
\hline
\end{tabular}

According to the present framework in India, one charging station will be set up at $25 \mathrm{Km}$ intervals on both sides of selected roads. According to the guidelines published, the tariff for the supply of electricity to EV charging stations will be determined by the appropriate commission, provided that the tariff is not more than the $15 \%$ above the average cost of supply. The state nodal agency will be responsible to fix the ceiling of the service charges levied by the PCS. Current fuel filling stations will be given priority and will be encouraged to set up charging stations. Company owned and company operated pumps will get further priority over privately owned pumps. The present EV charging scenario can be summarized as below:

- $\quad$ Buses with battery sizes $>100 \mathrm{kwh}$ will be sold with proprietary charging standards recommended by the battery manufacturer. These batteries will cost several million rupees and it is not advisable to charge from any PCS. Bus operators need to install the charging devices supplied (or recommended) by the bus manufacturer at bus depots and bus terminuses as required.

- Two wheelers comes with small size batteries which in many cases can be pulled out and taken to homes/offices/shops and charged from normal wall sockets; or can be connected to any PCS.

- Three wheelers are ideal candidates for battery swapping. Batteries may be charged in a large industrial scale facility and charged batteries are trucked to points of 3-wheeler concentration where a 3-wheeler driver can swap the used battery with a fully charged one. Three wheelers could also be charged from any PCS.

- $\quad$ Electric cars have the batteries on the chassis which are not suitable for swapping. Cars comes with various sizes of batteries - $11 \mathrm{kwh}$ (Mahindra e20) to 40kwh (Nissan leaf) to > 90kwh (tesla models). Electric cars can be charged at private charging facilities or PCS.

\section{CONCLUSION}

India has a lot to gain by shifting from ICE vehicles to EVs at the earliest. The major gains include reduction in environmental pollution, reduction in oil imports, improved national security, better economy and better utilization of renewable resources. Emissions from ICE powered motor vehicles are responsible for about two-thirds of air pollution in urban areas. The current ban on older fuel cars in some Indian cities already shows a positive influence on air quality, and this can only further improve with the large scale introduction of EVs. Today, the primary transport for villages, taking people to bus-stops on the highways or train-stations, is ICE three-wheelers. It is possible to quickly convert them to electric, providing clean transport in villages. EVs will create opportunities in durable and lightweight thermoplastics, higher demand for electricity, storage and many others. In addition, EV battery charging and swapping would create a large number of jobs throughout the country. Government of India is keen in creating a conductive atmosphere for Electric Mobility and recently the government made some major announcements for pushing electric mobility in India as part of the Union Budget 2019. It has been recommended to reduce the GST rate on electric vehicles from the current 12 per cent to five per cent in a bid to push the sale of EVs in the country. In addition, there will be an income tax deduction of $\square 1.5$ lakh on the interest paid on the loans taken to purchase electric vehicles. The advancement in EV technology, tightened environmental regulations and time bound efforts from the Government as well as automobile industries shall help in steady and smooth shift to Electric Mobility. 


\section{REFERENCES}

[1]. Fuad Un-Noor, Sanjeevikumar Padmanaban, Lucian Mihet-Popa, Mohammad Nurunnabi Mollah and Eklas Hossain, AComprehensiveStudyof Key Electric Vehicle (EV) Components, Technologies, Challenges, Impacts, and Future Direction of Development, Energies 2017, 10, 1217; doi:10.3390/en10081217

[2]. Reji Kumar Pillai, Reena Suri, Suddhasatta Kundu, Harpreet Singh, Shuvam Sarkar Roy and Shreekant Dhuri, ISGF White Paper, Electric VehicleChargingStations BusinessModelsforIndia, Version 1.0, September 2018

[3]. NITI Ayog, Global Mobility Summit, September 2018

[4]. https://powermin.nic.in/sites/default/files/webform/notices/scan0016\%20\%281\%29.pdf

[5]. https://www.eei.org/future/Pages/category.aspx?Category=Customer\%20Solutions

[6]. Yong, J.Y.; Ramachandaramurthy, V.K.; Tan, K.M.; Mithulananthan, N. A review on the state-of-the-art technologies of electric vehicle, its impactsandprospects. Renew. Sustain. Energy Rev. 2015,49,365-385.

[7]. Camacho, O.M.F.; Nørgård, P.B.; Rao, N.; Mihet-Popa, L. Electrical Vehicle Batteries Testing in a Distribution Network using Sustainable Energy. IEEE Trans. Smart Grid 2014,5,1033-1042.

[8]. Camacho, O.M.F.; Mihet-Popa, L. Fast Charging and Smart Charging Tests for Electric Vehicles Batteries using Renewable Energy. Oil Gas Sci. Technol. 2016,71, 13-25.

[9]. Chan, C.C. The state of the art of electric and hybrid vehicles. Proc. IEEE 2002,90,247-275.

[10]. Grunditz, E.A.; Thiringer, T. Performance Analysis of Current BEVs Based on a Comprehensive Review of Specifications. IEEE Trans. Transp. Electr. 2016, 2, 270-289.

\section{BIOGRAPHIES}

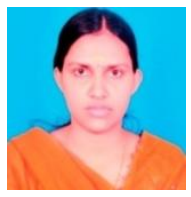

Indukala M.P. received B. Tech. degree in Electrical and Electronics Engineering from Nehru College of Engineering \& Research Centre, Thrissur under University of Calicut and M. E. in Power Electronics and Drives from Easa College of Engineering \& Technology, Coimbatore. Since August 2011, she is with St. Mary's Polytechnic College, Palakkad as Faculty in Department of EEE and became Head of the Department in 2013. She has authored the paper Study on Extent of Utilization of Renewable Energy Sources in Kerala. Her current research interest includes electric vehicles, renewable energy sources and renewable energy technologies. She is a Life Member of the Indian Society for Technical Education (ISTE).

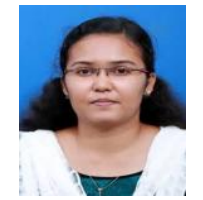

Bincy M. Mathew received B. Tech. degree in Electrical and Electronics Engineering from Mar Baselios College of Engineering \& Technology, Thiruvananthapuram under University of Kerala and M. Tech. in Power Electronics and Drives from Karunya Institute of Technology \& Sciences, Coimbatore. Since June 2016, she is with St. Mary's Polytechnic College, Palakkad as Faculty in Department of EEE. She has authored the paper Novel Single Phase Buck PFC Converter and the papers she has co-authored includes Modified Single Stage AC-AC Converter, Stability Analysis \& Limit Cycle Behaviour in DC-DC Boost Converter, Direct AC/ AC Converter and Study on Extent of Utilization of Renewable Energy Sources in Kerala. Her current research interest includes electric vehicles, renewable energy sources and renewable energy technologies. She is a Life Member of the Indian Society for Technical Education (ISTE). 